\title{
¿QUÉ SON LOS DIAGRAMAS GEOMÉTRICOS? UNA APROXIMACIÓN KANTIANO-PEIRCEANA
}

\author{
Álvaro Peláez \\ Universidad Autónoma Metropolitana/Cuajimalpa
}

Resumo: Que tipo de objetos saó os diagramas, os quais podem ser manipulados lógica e matematicamente e também servem para obter conhecimento? Neste artigo, proporei uma maneira de responder a esta pergunta. Sustentarei a hipótese, inspirada por Kant e Peirce, de que os diagramas são uma classe de objetos híbridos com um aspecto intelectual e outro sensivel. Os lógicos e matemáticos estão interessados e estudam uma certa estrutura que se exemplifica em um diagrama, embora não de maneira perfeita. Devido a seu caráter sensivel e a sua acessibilidade, tais diagramas permitem a manipulação e a experimentação, mas unicamente em virtude do tipo de relações por eles implicadas tornam possíveis juízos absolutamente universais.

Palavras-chave: Diagramas, esquemas, universal, geometria, Kant, Peirce

\begin{abstract}
What kind of objects are the diagrams, which can be manipulated logically and mathematically and through it to obtain knowledge? In this paper, I wish to propose a way to answer this question. I will sustain the view, inspired by Kant and Peirce, that diagrams constitutes a kind of hybrid objects with a intelectual and a sensible side. The logician or the mathematician are interested in an structure that is instantiated in the diagram, although not perfectly. This, in virtue of its sensible character and its accesibility allows the manipulation, the experimentation, but in virtue of kind of the relations that it entails, makes posible the production of judgments with universal scope.
\end{abstract}

Keywords: Diagrams, schemes, universals, geometry, Kant, Peirce 


\section{Introducción}

En las últimas dos décadas ha habido un interés renovado en la visualización en lógica y matemáticas ${ }^{1}$. Este renacimiento del interés en la visualización en las ciencias formales surge como consecuencia de desarrollos en áreas muy diferentes, incluyendo las ciencias computacionales, las matemáticas, la didáctica de las matemáticas, la psicología cognitiva, y la filosofía.

Es claro que cuando hablamos de un renacimiento del interés en la visualización, esto supone que la misma había sido relegada a un papel secundario en el pasado. Como es bien sabido, este rechazo se debió principalmente a la obra fundacional en geometría de finales del siglo XIX y comienzos del XX, especialmente relacionada al nombre de David Hilbert. Pero hablar de "renacimiento" también implica que en algún momento del pasado, el recurso a la visualización en las ciencias formales había sido valorado positivamente. En efecto, existe una larga tradición en filosofía, la cual se remonta a Platón, y que tal vez es inseparable de la geometría euclidiana, en la que las construcciones se consideraron como la piedra de toque del descubrimiento y la justificación matemáticas. La importancia de esta tradición ha sido reconocida y reevaluada en la literatura reciente sobre el tema, especialmente en lo tocante a los problemas epistemológicos ${ }^{2}$. Sin embargo, ha habido, desde mi punto de vista, una falta de atención a un problema que tal vez sea lógicamente anterior, a saber, el del estatus ontológico de los diagramas. En efecto, se ha discutido acerca del valor heurístico asociado a los diagramas, así como de su poder o falta de poder probatorio, pero está lejos de ser claro qué tipo de objetos son los diagramas que son aptos para la manipulación lógica y matemática y la obtención de conocimiento.

\footnotetext{
${ }^{1}$ En la introducción a su (2008), Paolo Mancosu sostiene que la filosofía tradicional de las matemáticas, así como la más reciente influida por aquella estuvo ocupada fundamentalmente con problemas ontológicos, desdeñando la práctica matemática misma. A partir de los años sesenta, con la obra de Lakatos primero, y luego Kitcher, Tymoczko y otros, se llevó a cabo una reacción contra esa filosofía de las matemáticas concebida como fundacional. La nueva atención prestada a los recursos visuales en las ciencias formales se imbrica fundamentalmente con esta segunda tradición. Véase, además de su (2008), su (1996). También son valiosas las contribuciones de Jill H. Larkin y Herbert A. Simon (1987), Sun-Joo Shin (1994), Eric Hammer (1994), Gerard Allwein y Jon Barwise (1996), Giaquinto (2007), y Miller (2007).

${ }^{2}$ Además de los ya citados trabajos de Giaquinto y Miller que discuten los problemas epistemológicos asociados a los diagramas teniendo en cuenta y reflexionando sobre autores del pasado como Kant, ha habido otras consideraciones apoyadas en otros filósofos como Peirce y Husserl. Véase: SHABEL (2003), y STJERNFELT (2007).
} 
En este artículo deseo proponer una forma de responder a esta pregunta. Sostendré la visión de que los diagramas constituyen una clase de objetos híbridos con un costado intelectual y uno sensible. El lógico o matemático está interesado y estudia una cierta forma de estructura que es ejemplificada en el diagrama, aunque no perfectamente. Este, en virtud de su carácter sensible y accesibilidad, permite la manipulación, la experimentación, pero en virtud del tipo de relaciones que entraña, posibilita la producción de juicios con alcance universal.

\section{Los diagramas en la práctica lógica y matemática}

La lógica, considerada como la disciplina encargada de estudiar las reglas de la inferencia válida, centró su atención, tradicionalmente, en una clase de información expresada en sólo una forma, a saber, la forma enunciativa. Las matemáticas, en tanto, a pesar de que en su práctica el recurso a otra clase de representaciones distintas que la enunciativa ha sido constante al menos desde Euclides, también consideró que lo importante de sus razonamientos no descansaba en esa clase de representaciones, las cuales a lo sumo tendrían un papel meramente heurístico. La búsqueda de la certeza y la exactitud condujo a lógicos y matemáticos a rechazar como un primitivismo el uso de recursos intuitivos en las disciplinas formales ${ }^{3}$. Sin embargo, parece ser un hecho que los seres humanos razonamos utilizando información que obtenemos y expresamos en otros medios. El trabajo actual tanto en las ciencias cognitivas, como en la lógica y las ciencias computacionales, no sólo han reafirmado este hecho, sino que han mostrado que los razonamientos que usan diagramas o representaciones visuales son tan sanos y completos como los que usan formas enunciativas ${ }^{4}$.

En este trabajo nos centraremos en un análisis y consideración de los diagramas geométricos, aunque conjeturamos que las mismas consideraciones pueden aplicarse a otros tipos de construcciones como: círculos de Euler,

\footnotetext{
${ }^{3}$ En geometría, por ejemplo, este rechazo comenzó en Descartes y se expresó de manera más contundente a finales del siglo XIX con la obra de Hilbert.

${ }_{4}$ Hay diferencias de énfasis al interior de los diversos debates que tienen en cuenta diferentes disciplinas. Por ejemplo, en las discusiones concernientes al papel de los diagramas en geometría euclidiana la idea defendida por Giaquinto, entre otros, es que existen pasos en las pruebas euclidianas que descansan enteramente en las construcciones y que no pueden ser sustituidas por supuestos análogos enunciativos. Véase su (2007). Por otro lado, en las discusiones al interior de la lógica, las afirmaciones parecen ser más de la índole de la siguiente de Barwise y Etchemendy: "no hay distinción en principio entre formalismos inferenciales que usan texto y los que usan diagramas. Uno puede tener sistemas formales rigurosos, lógicamente sanos y completos, basados en diagramas" (BARWISE \& ETCHEMENDY, 1995, p. 214).
} 
diagramas de Venn, cuadrados de Lewis Carroll, y grafos de existenciales de Peirce, así como a las variantes más recientes debidas a Shin (1994), Hammer y Shin (1998), y Stenning \& Lemon (2001), entre otros.

\section{3. ¿Qué son los diagramas geométricos?}

En este contexto, una primera respuesta a la pregunta que me he planteado sería: los diagramas son objetos sensibles espacio temporales. Sin embargo, si como solemos hacer, los consideramos como pertenecientes al campo de la lógica y las matemáticas, la respuesta, prima facie, podría no resultar satisfactoria. ¿Cómo es que objetos sensibles, siempre imperfectos y cambiantes, podrían ser los objetos de los que hablan las matemáticas, cuyas proposiciones parecen tratar de un reino de entidades eterno e inmutable? No obstante, también hemos asumido la inseparabilidad de la práctica lógica y matemática del uso de diagramas. Así, parece que enfrentamos un primer problema, a saber, que por un lado, reconocemos y aceptamos el carácter inherentemente constructivo de la geometría, mientras que por el otro rechazamos que dichas construcciones sean el objeto genuino de manipulación por parte del geómetra.

Como ya lo he adelantado, la solución que quiero proponer a este problema consiste en lo siguiente: considero que las construcciones geométricas constituyen una clase de objetos híbridos que al lado de sus propiedades meramente sensibles contienen otras típicamente estructurales que los hacen aptos para la manipulación matemática y la producción de juicios con alcance universal.

Podría decirse que ha habido tradicionalmente dos versiones de esta tesis: la primera sostiene que son las construcciones mismas, los diagramas efectivamente trazados, los que constituyen esa clase de objetos híbridos que mencionaba; por otro lado, están aquellos que, preocupados por salvaguardar a la geometría de las contingencias del mundo sensible, conciben esas entidades como objetos imaginarios. En lo que sigue voy a confrontar algunos de los autores que encuentro representativos de ambas posiciones y luego extraeré algunas consecuencias de esa discusión.

El primero que defendió la primera versión de la tesis fue Platón. En el Fedón, en su discusión sobre el "segundo mejor método", Platón plantea la necesidad de llegar al conocimiento de las esencias puras a través de sus manifestaciones fenoménicas. En efecto, después de considerar la propuesta de Anaxágoras, según la cual "la inteligencia es la norma y la causa de todos los seres", por lo cual quien desea conocer las causas de las cosas sólo debe concebir la mejor manera en la que ellas pueden existir, Sócrates se declara incompetente para aplicar dicho método y plantea la siguiente 
analogía: "Cansado de examinar todas las cosas, creí que debía estar prevenido para que no me sucediese lo que a los que miran un eclipse de sol; que pierden la vista si no toman la precaución de observar en el agua o en cualquier otro medio la imagen de este astro." (Idem, p. 118), y agrega: "Me convencí de que debía recurrir a la razón y buscar en ella la verdad de todas las cosas. Quizás la imagen de que me sirvo para explicarme no es enteramente exacta; porque yo mismo no estoy conforme en que el que mira las cosas en la razón las mire más aún por medio de otra cosa que el que las ve en sus fenómenos" (Idem, p. 118). Desde mi punto de vista, cuando Sócrates habla del "ser" de las cosas, "lo que cada una es actualmente" o de "sus verdaderos elementos", se está refiriendo a las clases de estructuras que las cosas en cuestión ejemplifican. Su visión es que esas clases de estructuras se estudian mejor por medio del intelecto, pero esto no implica que descubrimos que las cosas tienen esta estructura sólo por medio del intelecto. Por ejemplo, nuestra experiencia con la construcción y medida de formas sensibles nos conduce al estudio de la estructura geométrica, aunque la forma más apropiada de estudiar dicha estructura fuera sólo por medio del intelecto. Con esto no quiero decir, por supuesto, que las cosas sensibles ejemplifiquen de manera perfecta las propiedades estructurales de los objetos geométricos, pero sabemos desde la práctica geométrica más básica que no es una condición, para obtener resultados geométricos, que las construcciones sensibles que usamos posean algún grado de perfección. Aprendemos geometría, por ejemplo, considerando diagramas, y aprendemos cómo aplicar la geometría a esas figuras así como a otras cosas. Pero también vemos en algún momento que las marcas sobre el pizarrón o las líneas del agrimensor no son realmente objetos geométricos. Sin embargo, continuamos siendo capaces de aplicar a ellos la geometría, vemos algunas figuras como segmentos de línea recta, a otras como círculos, a otras como más largas, etc.

Esto es compatible con República VI, donde Platón aclara el proceder de los geómetras mediante la conocida analogía de la línea. Según esta analogía, así como en el reino de lo visible existen las cosas y sus imágenes, en el reino de lo inteligible las cosas visibles son imágenes de las ideas puras, y el vehículo mediante el cual se asciende a estas últimas. Así, dice Platón: "Sabes, por consiguiente, que se sirven de figuras visibles y hacen discursos acerca de ellas, aunque no pensando en estas sino en aquellas cosas a las cuales estas se parecen, discurriendo en vista al Cuadrado en sí y a la Diagonal en sí, y no en vista de la que dibujan... y de estas cosas que dibujan se sirven como imágenes, buscando divisar aquellas cosas en sí que no podrían divisar de otro modo que con el pensamiento" (PLATÓN, 1986, p. 336). 
Ahora bien, permítaseme ahora considerar a Kant como representante de la segunda versión de la tesis. Comenzaré con una cita que ilustra la adhesión del filósofo de Könisberg al método constructivo:

Demos al filósofo el concepto de triángulo y dejémosle que halle a su manera la relación existente entre la suma de sus ángulos y un ángulo recto... Dejemos que sea ahora el geómetra el que se ocupe de esta cuestión. Comienza por construir en seguida un triángulo. Como sabe que la suma de dos ángulos rectos equivale a la de todos los ángulos adyacentes que pueden trazarse desde un punto sobre una línea recta, prolonga un lado del triángulo y obtiene dos ángulos adyacentes que, sumados, valen dos rectos. De estos dos ángulos divide el externo trazando una paralela al lado opuesto del triángulo y ve que surge de este modo un ángulo adyacente externo igual a uno interno; y así sucesivamente (A717-B745).

Lo que Kant está describiendo aquí es la siguiente construcción:

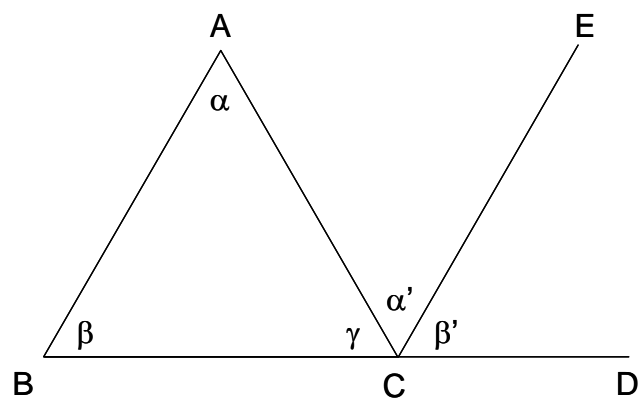

Dado un triángulo $\mathrm{ABC}$, se prolonga el lado $\mathrm{BC}$ a $\mathrm{D}$ y luego se traza CE paralela a AB. Entonces uno nota que $\alpha=\alpha^{\prime}$ y $\beta=\beta$, de modo que $\alpha+$ $\beta+\gamma=\alpha^{\prime}+\beta^{`}+\gamma=$ dos rectos.

Luego agrega Kant: "A través de una cadena de inferencias y guiado siempre por la intuición, el geómetra consigue así una solución evidente y, a la vez, universal del problema" (A717-B745).

Ahora bien, ¿qué tipo de objeto está pensando Kant que se obtiene a través de esta construcción? En la cita final, aparece, de manera clave, el término "intuición", y como es bien sabido, desde el punto de vista de Kant, las intuiciones, sean a priori o empíricas, lo son de particulares. Pero si esto 
es así, ¿qué sentido tendría acompañar esta asunción con la idea de que la solución del geómetra al problema es "universal"? Wilfrid Sellars ha señalado $^{5}$, con razón a mi modo de ver, que Kant aplica el término "intuición" tanto a representaciones que son formadas por la actividad sintetizadora de la imaginación productiva, como a representaciones puramente pasivas de la facultad de receptividad, que son la materia que la imaginación productiva toma en cuenta. Quiero sugerir que cuando Kant habla de construcciones geométricas y emplea el término intuición para referirse a ellas, lo está usando en el primer sentido, más familiar a su uso del término "esquema", es decir, una representación en cuya determinación participa la imaginación productiva guiada por el entendimiento ${ }^{6}$.

¿Cómo explica Kant este proceso constructivo? En la Doctrina trascendental del método, en la Crítica de la razón pura, donde se ocupa de caracterizar el método matemático, dice: "Construir un concepto significa presentar la intuición a priori que le corresponde" (KANT, 1978, A714B742). "Construir" equivale aquí a la transición desde un concepto general hasta una intuición que representa al concepto, con la condición de que esto se efectúe sin recurrir a la experiencia. Veamos esto con algo de cuidado. Dice Kant a continuación: "Para construir un concepto hace falta, pues, una intuición no empírica que, consiguientemente, es, en cuanto intuición, un objeto singular, a pesar de lo cual, en cuanto construcción de un concepto (representación universal), tiene que expresar en su representación una validez universal en relación con todas las posibles intuiciones pertenecientes al mismo concepto" (A714-B742).

De acuerdo con un presupuesto fundamental de la filosofía kantiana, a todo concepto debe corresponderle una intuición, la cual, por supuesto, viene suministrada por la sensibilidad. Al comienzo mismo de la Estética trascendental, Kant define a la intuición como "el modo por medio del cual el conocimiento se refiere inmediatamente a (los) objetos" (A19-B33), lo cual no parece dejar dudas acerca de que este tipo de representaciones lo son de objetos particulares. En el caso de las matemáticas, que constituye una clase de conocimiento universal y necesario, sus intuiciones han de proveerse a priori. Dado que estas constituyen el objeto que otorga

\footnotetext{
5 Vid. su (1967).

${ }^{6}$ La exposición de este punto coincide con mi (2008). Asimismo, considero que esta parece haber sido la forma en que el propio Frege entendió a Kant, cuando en los Grundlagen afirma que "En geometría, por lo tanto, es totalmente inteligible que las proposiciones generales deben ser derivadas de la intuición; los puntos, líneas o planos que intuimos no son particulares en lo absoluto, que es lo que les posibilita estar como representantes de la totalidad de su clase" (20). En mi (2010) trato de hacer inteligibles estas afirmaciones de Frege.
} 
significado al concepto y así el objeto al que este refiere, no pueden ser, desde mi punto de vista, meramente particulares, sino, como dice Kant, unas que expresen las propiedades compartidas por todas las intuiciones pertenecientes al mismo concepto. Al hablar de propiedades compartidas, aclara Kant unas líneas más abajo, no nos referimos a las propiedades prescindibles de una cierta clase de objetos, como serían, en un triángulo, la magnitud de los lados y de los ángulos, sino a las propiedades universales y necesarias de los mismos. Esta intuición, según él, "apunta siempre al simple acto de construir el concepto" (A714-B742), esto es, constituye una representación cuyo fin es la expresión de un concepto. Por ello no puede ser meramente particular.

Esta representación intuitiva pero determinada conceptualmente, la cual constituye el objeto del concepto, y es construida, en palabras de Kant "sin tomar el modelo de una experiencia" (Idem), es aquello a lo que Kant llamó el esquema del concepto ${ }^{7}$. Así lo expresa en el mismo apartado: "Por ello, así como este singular se halla determinado por ciertas condiciones universales de la construcción, así también el objeto del concepto, al que dicho singular corresponde como su mero esquema, tiene que concebirse como universalmente determinado" (Idem).

En la sección sobre el esquematismo de los conceptos puros del entendimiento de la CRP, Kant parte del reconocimiento de que los esquemas son producto de la imaginación, pero enfatiza de inmediato que, dado que la imaginación tiene aquí la función de sintetizar una multiplicidad de intuiciones, su resultado no puede ser una intuición particular. Así, un esquema ha de ser distinguido cuidadosamente de una imagen, la cual en sentido estricto lo es siempre de un objeto particular. En el ejemplo que proporciona Kant, los cinco puntos... constituyen una imagen, una representación sensible del numero cinco, lo que no quiere decir que constituya, desde su punto de vista, la intuición relacionada con el concepto de cinco. A favor de ello, alega Kant que dicha representación particular nunca podría ser comparada con el concepto. Es decir, nunca podría constituir el objeto genuino de referencia del concepto. Y ejemplifica una vez más con un caso tomado de la geometría: "Ninguna imagen de un triángulo se adecuaría jamás al concepto de triángulo en general. En efecto, la imagen no alcanzaría la universalidad conceptual que hace que el

\footnotetext{
${ }^{7}$ En su (2001) Tyler Burge argumenta que en Kant la generalidad de las proposiciones geométricas basadas en la intuición sólo es posible por una especie de capacidad de abstracción que opera sobre las figuras individuales. Desde mi punto de vista, no sólo no hay evidencia textual alguna que avale dicha lectura, sino que la idea misma de abstracción no es algo que esté presente en la teoría kantiana de la formación de conceptos.
} 
concepto sea válido en relación con todos los triángulos, sean rectángulos, oblicuángulos, etc., sino que siempre estaría limitada a una sola parte de esa esfera. El esquema del triángulo no puede existir más que en el pensamiento, y significa una regla de síntesis de la imaginación respecto de figuras puras en el espacio" (A141-B180).

En mi opinión, Kant se encontraba muy cerca de concebir las construcciones geométricas como los diagramas efectivamente trazados, sin embargo, como parece seguirse del final de la cita anterior, no dio ese paso, tal vez preocupado por salvaguardar las matemáticas de las contingencias empíricas, manteniéndolas al nivel de entidades mentales. Al igual que ya lo había hecho con mucha anterioridad Proclo $^{8}$, Kant parece distinguir entre una materia sensible asociada a la imaginación, y la materia sensible asociada al mundo material, constituyendo la primera el componente sensible de los esquemas. Como acabo de decir, no encuentro mayor justificación para esta consideración que una suspicacia por parte de Kant hacia el mundo material como genuino instanciador de estructuras conceptuales.

Por este camino se dirigió Charles Sanders Peirce, a quien me referiré a continuación. Permítaseme comenzar con una distinción ciertamente conocida y para algunos análoga a la distinción kantiana entre lo analítico y lo sintético 9 : la distinción entre razonamiento corolarial y teoremático. Según Peirce, los filósofos desde Aristóteles han privilegiado el método de la demostración directa, una demostración que no usa más que conceptos generales y no concluye sino algo que quedaría absorbido por una definición si todos sus términos estuvieran precisa y explícitamente definidos. Los matemáticos, por su parte, enuncian como simples corolarios las proposiciones que pueden deducirse de otras por el tipo de razonamiento glorificado por los filósofos. Equivalen a aquellas proposiciones que Euclides no consideró de mención especial y que sus editores añadieron a su texto, intercalándolas con una coronita o corola al margen. Para probar los teoremas, se requiere otro método de razonamiento, en el que no podemos limitarnos a términos generales. Dice Peirce en su ensayo de 1902, "La esencia de la matemática": "Hace falta sentar o imaginar algún esquema o diagrama particular y determinado: en geometría, alguna figura compuesta por líneas nombradas por letras... Este esquema se construye de tal modo que sea conforme con alguna hipótesis enunciada en términos generales en la tesis del teorema" (PEIRCE, 1974, p. 32). Sin embargo, desde el punto de

${ }^{8}$ Cf. su (1970).

${ }_{9}^{9}$ Me refiero a Hintikka. Véase su (1983) y su (1998). 
vista de Peirce, aunque el esquema en cuestión sea construido de acuerdo al precepto contenido en la tesis, no podemos esperar que la afirmación del teorema sea evidente ni siquiera para dicho esquema particular. En su opinión, "es necesario HACER algo. En geometría se dibujan líneas auxiliares. En álgebra se practican transformaciones permitidas. A continuación entran en juego las facultades de observación. Se percibe alguna relación entre las partes del esquema" (Idem, p. 33). A este modo de razonamiento le llama Peirce "teoremático", el cual depende siempre de la experimentación con esquemas particulares. Pero, ¿qué son para Peirce estos diagramas? Para comenzar, como es bien sabido, Peirce considera que un diagrama es un signo, esto es, algo que sirve para expresar conocimiento de alguna otra cosa, y como todo signo, tiene un aspecto material, su cualidad material, como la llama Peirce. Dice: “Así, una palabra impresa es negra, tiene un cierto número de letras y esas letras tienen ciertas formas. A tales caracteres de un signo las llamo su cualidad material" (PEIRCE, 1991, p. 141). Pero, por supuesto, un signo no es solo eso, sino que tiene dos caracteres más, a saber, lo que Peirce llama su aplicación puramente demostrativa, que tiene que ver con la conexión causal existente entre el signo y el hecho significado, y la referencia a un sujeto que considera que el signo es un signo de algo, es decir, la referencia a una mente que conoce las cualidades materiales del signo y sus conexiones causales con el hecho del que es signo.

Pero Peirce agrega que un diagrama es un signo de una clase especial, es lo que él llama un ícono. Los íconos son signos cuya virtud significante se debe simplemente a su cualidad. Esta cualidad equivale a caracteres compartidos entre signo y objeto. Dice Peirce que un ícono es un signo que refiere al objeto que denota meramente en virtud de caracteres de suyo propio y que posee, tanto si dicho objeto existe actualmente o no. Es cierto que a menos que haya tal objeto, el ícono no actúa como signo, pero esto no tiene nada que ver con su carácter de signo. Algo, cualquier cosa, sea cualidad, individuo existente, o ley, es un ícono de otra cosa, en la medida en que es como dicha cosa y es usada como signo de la misma. A su vez, Peirce distingue tres clases de íconos: imágenes, diagramas y metáforas. Mientras que las imágenes representan a su objeto a través de cualidades simples y las metáforas lo hacen a través de una semejanza encontrada en algo más, los diagramas representan su objeto a través de un bosquejo estructural de relaciones. Dice Peirce en sus Nuevos elementos: "Un diagrama es un ícono o imagen esquemática que incorpora el significado de un predicado general..." (PEIRCE, 1998, p. 303). Veamos esto con cuidado. 
Desde el punto de vista de Peirce, las matemáticas hacen un uso peculiar de la abstracción. En su opinión, bajo el término abstracción se han entendido tradicionalmente dos actividades de pensamiento ciertamente diferentes y que él distingue cuidadosamente: una, que llama abstracción precisiva, asociada aun a la percepción más trivial, implica una cierta corrección o precisión de la percepción; la segunda, a la que llama "abstracción hipostática", consiste en tomar un rasgo de uno o varios perceptos, luego de haber prescindido de los demás, y elevarlo al estatus de un predicado. Es decir, un predicado o concepto genérico no es más que una relación entre ciertos aspectos de los particulares.

Ahora bien, cuando Peirce dice que un diagrama es un ícono o imagen esquemática que incorpora el significado de un predicado general, lo que parece estar significando es que el diagrama es un ícono de un conjunto de objetos relacionados de acuerdo con una regla, o como él mismo lo expresa en otro lado, relacionados "racionalmente". Esto es, el diagrama "muestra" la relación que existe entre ciertos aspectos de los particulares, es decir, captura el proceso abstractivo mismo, el cual supone un recorrido por una diversidad y el hallazgo de una relación. En este sentido, el diagrama es una imagen esquemática debido a que al tiempo que pertenece al campo de lo perceptible, expresa ciertas relaciones racionales. Peirce reconoce aquí la raigambre kantiana de su concepción. En "Prolegómenos para una apología del pragmaticismo", dice: “... y así el diagrama icónico y su interpretante simbólico inicial tomados juntos constituyen lo que Kant llamaba esquema, que es por un lado, un objeto capaz de ser observado, mientras que por el otro lado es general" (Citado en STJERNFELT, 2007, p. 94). Es claro que la diferencia con Kant es que este, como señalé anteriormente, no dio el paso que lo conduciría a reconocer que el diagrama sensible es el esquema, manteniendo a este último al nivel de una entidad meramente imaginada.

Así, el signo material dotado de contenido conceptual es el objeto de manipulación por parte del geómetra. Pero Peirce es explícito en cuanto a dónde radica el interés del matemático, a saber, en las propiedades estructurales del diagrama. Dice en "Las tres ciencias normativas": "Pero comenzando con ejemplos apropiados y procediendo desde allí hacia otros, uno encuentra que el diagrama mismo en su individualidad no es con lo que el razonamiento está interesado" (PEIRCE, 1998, p. 206). En "Prolegómenos para una apología del pragmaticismo", trata este asunto en analogía con los experimentos de la ciencia empírica, donde estos son vistos como preguntas que se hacen a la naturaleza. Desde su punto de vista, la manipulación con diagramas también constituye una clase de preguntas que 
hacemos a ciertos hechos. Pero lo que es más importante, en relación con el punto que me interesaba, es que Peirce dice que si bien existe una diferencia entre experimentar con diagramas y hacerlo con hechos químicos, hay algo en común, a saber, que tanto el químico como el matemático, están interesados no en las propiedades individuales de aquello que se encuentran manipulando, sino en los hechos generales que expresan. En química, dice Peirce, no es el ejemplar mismo que se encuentra investigando, sino, por ejemplo, la estructura molecular; en matemáticas, por su parte, el objeto bajo investigación es la forma de una relación, esto es, la forma de la relación entre las partes del diagrama.

\section{Conclusiones}

Permítaseme para finalizar extraer algunas conclusiones de mi exposición anterior de modo de enriquecer mi temprana asunción de que los diagramas geométricos constituyen una clase de objetos híbridos, con un aspecto sensible y otro intelectual, que los hace particularmente apropiados para la manipulación matemática.

a) En primer lugar, asumo la idea de Peirce, que también está de alguna manera en Platón y Kant, de que los diagramas son signos. La palabra de Platón para señalar este aspecto de los diagramas es que ellos "participan" de los atributos de otras entidades; Kant y Peirce prefieren hablar de que "representan" otras entidades.

Dado su carácter de signo, y de acuerdo a la propia definición de Peirce, distinguimos en primer lugar en todo signo su aspecto material. Pero en virtud de que en general razonamos acerca del mundo sensible en términos de conceptos, los diagramas, que son objetos construidos por nosotros u objetos a los cuales nosotros mismos asignamos un significado en tanto signo, poseen un aspecto intelectual que es el objeto genuino de atención del matemático. Ya Platón se había planteado el problema de la relación entre lo sensible y lo intelectual, dado que el primer dominio se encuentra afectado de una indeterminación fundamental. Su respuesta es que aunque las figuras sensibles sean toscamente trazadas no por ello no poseen las propiedades en las cuales participan. Las únicas instancias de una proposición geométrica general son las figuras sensibles, imperfectas como ellas son. Pero la verdad de esa proposición general no puede, por supuesto, derivarse de la verdad de sus instancias, por lo que el conocimiento verdadero es acerca de las formas en las que los diagramas participan.

b) En segundo lugar, y relacionado con lo anterior, el diagrama mismo, como el esquema kantiano, a pesar de su observacionalidad, no 
debe ser considerado estrictamente como una figura particular: ya antes de adscribir al diagrama cualquier contenido o referencia, toma lugar un proceso crucial de abstracción que permite que el ícono en cuestión sea interpretado como una instanciación de una clase, al colocar entre paréntesis todo rasgo accidental del ejemplar. "Uno contempla el diagrama", dice en otro lugar Peirce, "y de una vez se prescinde de los caracteres accidentales que no tienen ninguna significación". Cuando, por ejemplo, vemos una figura geométrica trazada en el pizarrón, inmediatamente prescindimos de los accidente empíricos que tienen que ver con su trazado, esto es, hacemos abstracción del carácter vacilante de las líneas, de las dimensiones de las mismas, de su color, etc. Esta lectura de las propiedades esenciales de las figuras depende del conjunto de reglas, explícitas o implícitas, que gobiernan su construcción. Por ello, puede decirse que diferentes diagramas pueden, en virtud de que están gobernados por las mismas reglas, significar lo mismo. Independientemente de las propiedades sensibles que el diagrama posee, exhibe una cierta estructura determinada conceptualmente que lo hace una instancia de una clase.

c) En tercer lugar y para terminar, me interesa detenerme en la cuestión de la necesidad del proceso diagramático. Si un diagrama es un representante de un símbolo, siendo éste un signo para un concepto general, aquello significa que la construcción de un diagrama procede de acuerdo con la regla contenida en el símbolo, esto es, en el concepto. Así, un diagrama, siendo un signo particular, expresa la regla contenida en el concepto, y por ende expresa una conexión universal. Esta conexión esencial del diagrama con el concepto, define una propiedad más de los diagramas que me interesa resaltar, su aspecto esencialmente normativo. Está más allá del alcance de cualquier diagramatización representar símbolos inconsistentes: la regla conceptual representada por el símbolo, el cual a su vez constituye la regla para la construcción de sus instancias diagramáticas constituye una demanda necesaria y universal de la mente. Así, por ejemplo, el símbolo gramaticalmente correcto "cuadrado redondo", que implica una regla para conectar las dos cualidades icónicas "cuadrado" y "redondo", se revela como inconsistente en tanto intentamos construir un diagrama para expresar las propiedades en una y la misma figura. En otras palabras, el diagrama, en la medida en que es posible, en el sentido de que es consistente, expresa la norma contenida en el concepto.

\section{Referencias}


ALLWEIN, G., \& BARWISE, J. Logical Reasoning with Diagrams. Oxford: Oxford University Press, 1996.

BARWISE, J.; ETCHEMENDY, J. "Heterogeneous Logic". In: GLASGOW, J.; NARAYANAN, N. H.; CHANDRASEKARAN, B. (eds.). Diagrammatic Reasoning: Cognitive and Computational Perspectives. Cambridge: The MIT Press, 1995.

BURGE, T. "Frege on Apriority". In: Building on Frege. New Essays on Sense, Content, and Concept. NEWEN, A., NORTMANN, U.; STUHLMANN-LAEISZ, R. (eds.). Stanford: CSLI Publications, 2001.

COXETER, H. S. M. Projective Geometry. Nueva York: Springer-Verlag. FOWLER, D. The Mathematics of Platos's Academy. Oxford: Oxford University Press, 1999.

GIAQUINTO, M. Visual Thinking in Mathematics. Oxford: Oxford University Press, 2007.

HAMMER, E. "Reasoning with Sentences and Diagrams". Journal of Formal Logic, Vol. 35, n. 1, 1994.

HINTIKKA, J. "C. S. Peirce's "First Real Discovery" and its Contemporary Relevance". In: FREEMAN, E. (ed.). The Relevance of Charles Peirce. The Hegeler Institute, La Salle, 1983.

HINTIKKA, J. "El lugar de C. S. Peirce en la historia de la lógica". In: El viaje filosófico más largo. De Aristóteles a Virginia Woolf. Barcelona: Gedisa, 1998.

KANT, I. Crítica de la razón pura. Madrid: Alfaguara, 1988.

1985. . Prolegómenos a toda metafísica del porvenir. México: Porrúa,

Larkin, J., \& SIMON, H. "Why a Diagram is (Sometimes) Worth Ten Thousand Words". Cognitive Science 11, 1987, p. 65-99.

MANCOSU, P. Philosophy of Mathematics and Mathematical Practice in the Seventeenth Century. Oxford: Oxford University Press, 1996.

. The Philosophy of Mathematical Practice. Oxford: Oxford University Press, 2008.

MILLER, N. Euclid and His Twentieth Century Rivals. Diagrams in the Logic of Euclidean Geometry. CSLI Publications, 2007.

PEIRCE, Ch. S. "La esencia de la matemática". In: La forma del pensamiento matemático. Barcelona: Grijalbo, 1974.

"On the Nature of Signs". In: Peirce on Signs: Writings on Semiotic. The University of North Carolina Press, 1991.

. The Essential Peirce. Selected Philosophical Writings Vol. 2 (1893-1913), Indiana University Press: Indiana y Bloomington, 1998. 
PELÁEZ, A. "Geometría, esquemas, e idealización: una módica defensa de la filosofía de la geometría de Kant". Revista de filosofía, Vol. LXIV, p. 6579, Universidad de Chile, 2008.

"Kant y Frege sobre geometría: intuición, esquemas y generalidad". In: Perspectivas filosóficas. REY, C.; MORENO, I. (comps.). Montevideo: ANEP, 2010.

PLATÓN. Fedón. Madrid: Edaf, 1984.

. República. Madrid: Gredos, 1986.

PROCLO. A Commentary on the First Book of Euclid's Elements. Princeton: Princeton University Press, 1970.

SELLLARS, W. Science and Metaphysics. Variations on Kantian Themes. Atascadero, Ridgeview Pub. Company, 1967.

SHABEL, L. Mathematics in Kant's Critical Philosophy. Reflections on Mathematical Practice. Londres: Routledge, 2003.

STJERNFELT, F. Diagrammatology. An Investigation on the Borderlines of Phenomenology, Ontology, and Semiotics. Springer: Verlag, 2007.

SUN-JOO SHIN. The Logical Status of Diagrams. Cambridge: Cambridge University Press, 1994. 